\title{
Incorporação de resultados de avaliação pós-ocupação de escola em modelo BIM
}

\author{
CARDOSO, Grace (1); \\ BERNARDES, Marina (2); \\ SARAIVA, Naísa B. M. (3);
}

(1) Programa de Pós-Graduação Stricto sensu em Arquitetura e Urbanismo (PPGARQIMED), doutora em Ciências da Engenharia Ambiental, e-mail:grace.cardoso@imed.edu.br

(2) Universidade Federal de Santa Catarina (UFSC), mestranda em Arquitetura e Urbanismo, e-mail: arq.marinabernardes@gmail.com

(3) Faculdade Meridional (IMED), bolsista de iniciação científica em Arquitetura e Urbanismo, e-mail: saraiva.naisa@hotmail.com

\begin{abstract}
RESUMO
A utilização da plataforma BIM (Building Information Modeling) têm se destacado como ferramenta de análise e integração de resultados de APO (Avaliação Pós-Ocupação), pois facilita a interpretação de resultados graficamente e organiza as informações, de forma a contribuir para a criação de banco de dados. Este trabalho apresenta resultados de APO em relação ao conforto térmico e lumínico de uma escola de Passo Fundo/RS, a partir das análises realizadas com a plataforma BIM. Por ser uma abordagem multimétodos, a aplicação da APO envolveu medições in loco de temperatura, ventilação, umidade e iluminação. Com os resultados coletados foi possível apresentar as informações obtidas nas medições, a partir de uma escala de cores integrada ao modelo BIM, que permitiu a visualização do conforto nos ambientes analisados. Portanto, as ferramentas de APO aliadas à plataforma BIM poderão qualificar o processo de APO nas edificações a partir do melhoramento do banco de dados estabelecido.
\end{abstract}

Palavras chave: Avaliação Pós-Ocupação; Arquitetura escolar; Building Information Modeling.

\begin{abstract}
The use of the BIM (Building Information Modeling) platform has stood out as a tool for analysis and integration of APO (Post-Occupancy Assessment) results, since it facilitates the interpretation of results graphically and organizes the information, in order to contribute to the creation of This work presents results of APO in relation to the thermal and light comfort of a school in Passo Fundo, RS, based on the analyzes carried out with the BIM platform. Because it is a multi-method approach, the APO application involved in-situ measurements of temperature, ventilation, humidity, and illumination. With the results collected, it was possible to present the information obtained in the measurements, from a color scale integrated to the BIM model, which allowed the visualization of comfort in the environments analyzed. Therefore, the APO tools allied to the BIM platform may qualify the APO process in the buildings from the improvement of the established database
\end{abstract}

Keywords: Post-occupation evaluation; School architecture; Building Information Modeling. 


\section{INTRODUÇÃO E JUSTIFICATIVA}

A principal função da edificação é propiciar a seus usuários proteção e conforto para o desenvolvimento de suas atividades (OCHOA, ARAÚJO E SATTLER, 2012). Neste sentido, a avaliação Pós-Ocupação (APO) estuda o ambiente construído durante a sua utilização, ou seja, quando passa a cumprir a função pela qual foi construído (CARDOSO; VISENTIN; BENINCÁ, 2017). Estudos de APO buscam uma crítica à realidade de determinado local, urbanos ou edificados, com relação aos aspectos técnicos, físicos, funcionais e comportamentais, a partir de medições e verificações in loco, e da percepção dos usuários a partir destes mesmos aspectos (VISENTIN; CARDOSO; BENINCÁ, 2017). Os resultados permitem aos pesquisadores diagnosticarem a situação do ambiente construído e proporem soluções a curto, médio ou longo prazo, visto que estes espaços deveriam passar por contínuos programas de manutenção e adequação às necessidades dos usuários (PREISER; VISCHER, 2005; VISENTIN; CARDOSO; BENINCÁ, 2017).

Para Cardoso; Visentin e Benincá (2017), a APO é um exemplo de que os conceitos de comportamento, desempenho e conforto térmicos estão interligados e fazem parte do conhecimento sobre ambientes construídos, pois relaciona a análise subjetiva dos usuários aos resultados das avaliações de comportamento e desempenho térmicos dos materiais e sistemas construtivos. Além disso, a APO possibilita a criação de uma base de dados para retroalimentação do processo de projeto.

A lacuna de credibilidade entre as condições reais das edificações e o desempenho estimado, pode ser solucionada por meio do conhecimento adiquirido em estudos de APO já realizados (GÖÇER; HUA; GÖÇER, 2015). Todavia, apenas 7\% das empresas implementam APO em seus processos de projeto, uma vez que existe dificuldade em organizar as informações para análises de projetos posteriores (PEREIRA et al., 2017).

Os métodos e ferramentas de APO são de fundamental importância para a evolução das construções, e desta forma, a tecnologia BIM (Building Information Modeling) vem ao encontro do tema, pois baseia-se em um banco de dados reunindo uma diversidade de informações importantes para diferentes etapas do processo de projeto (PEREIRA et al., 2017).

Diante disso, este trabalho ${ }^{1}$ tem como objetivo explorar para fins de teste a utilização da plataforma BIM para análise dos resultados da Avaliação Pós-Ocupação, realizada em uma escola de educação infantil de Passo Fundo-RS.

\subsection{APLICAÇÃO DE CONCEITOS DE APO EM SOFTWARE BIM}

BIM (Building Information Modeling) representa um conjunto de tecnologias, processos e políticas que permite a atuação colaborativa dos agentes influentes no ciclo de vida de uma edificação em um ambiente virtual, possibilitando aos projetistas o controle acerca das informações de diversas disciplinas construtivas e com isso, maior detalhamento e consistência de dados durante as etapas de desenvolvimento das edificações (SUCCAR, 2013; PEREIRA et al., 2017).

Neste sentido, para Göçer, Hua e Göçer (2015) existe potencial na utilização da plataforma BIM para análise e transmissão de feedback de informações nas etapas de tomada de

\footnotetext{
${ }^{1}$ Artigo elaborado a partir da atividade realizada na disciplina de Avaliação Pós-Ocupação e - Processo de Projeto, do Programa de Pós-Graduação Stricto sensu em Arquitetura e Urbanismo (PPGARQ-IMED), no período de 2017.1, pelos alunos a seguir: PEREIRA, Bruna S.; MOREIRA, Denise A.; PAZINI, Ernani Z.; SARAIVA, Gabriela H.; SILVA, Juliano L.; COSTA, K.; FERRI, Mariane B.; MELLO, Marina B.; ZARDO, Paola; FOGAÇA, Paula; WINTER, Renato.
} 


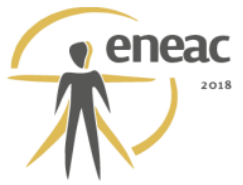

decisão de projeto e verificação do ciclo de vida das edificações. Os autores propõem uma metodologia baseada em conceitos de APO para incorporação de dados relacionados à percepção de usuários e medições in loco nos ambientes BIM, de modo a promover a criação de um banco de dados de informações ligadas à modelos (GÖÇER; HUA; GÖÇER, 2015, PEREIRA et al., 2017).

Já para Gerrish et al. (2017) a incorporação de informações a partir de medições técnicas à plataforma BIM, possibilita a atualização do banco de dados. Na medida em que estes bancos de dados são enriquecidos com os coletados em campo, possibilitam aos projetistas tomar decisões cada vez mais bem informadas acerca do desempenho esperado em suas edificações (PEREIRA et al., 2017).

\section{MÉTODO}

A pesquisa é de caráter exploratória e foi desenvolvida com dados primários, com coletas in loco de conforto térmico e lumínico de oito salas do primeiro pavimento da Escola Municipal de Educação Infantil André Zaffari, em Passo Fundo-RS. As medições foram realizadas por meio de equipamentos próprios para cada parâmetro do conforto ambiental estudado, apresentados a seguir.

\subsection{Ambiente de pesquisa}

O local de pesquisa denomina-se Escola Municipal de Educação Infantil André Zaffari, a qual é destinada a atender as necessidades de demanda do bairro Vila Luiza na cidade de Passo Fundo - RS, bem como dos bairros do entorno (Figura 01) (PEREIRA et al., 2017). O projeto tem como essência ser uma escola referência com conceitos inovadores, tais como integração à natureza e sustentabilidade. Através de alguns elementos de mobiliário e acessibilidade, possibilita uma arquitetura interativa com o objetivo de desenvolver os potenciais da criança. A Avaliação Pós-Ocupação realizada na escola André Zaffari foi conduzida a partir de medições in loco, e representação de dados por meio de software BIM (PEREIRA et al., 2017).

Figura 01: Escola Municipal de Educação Infantil André Zaffari

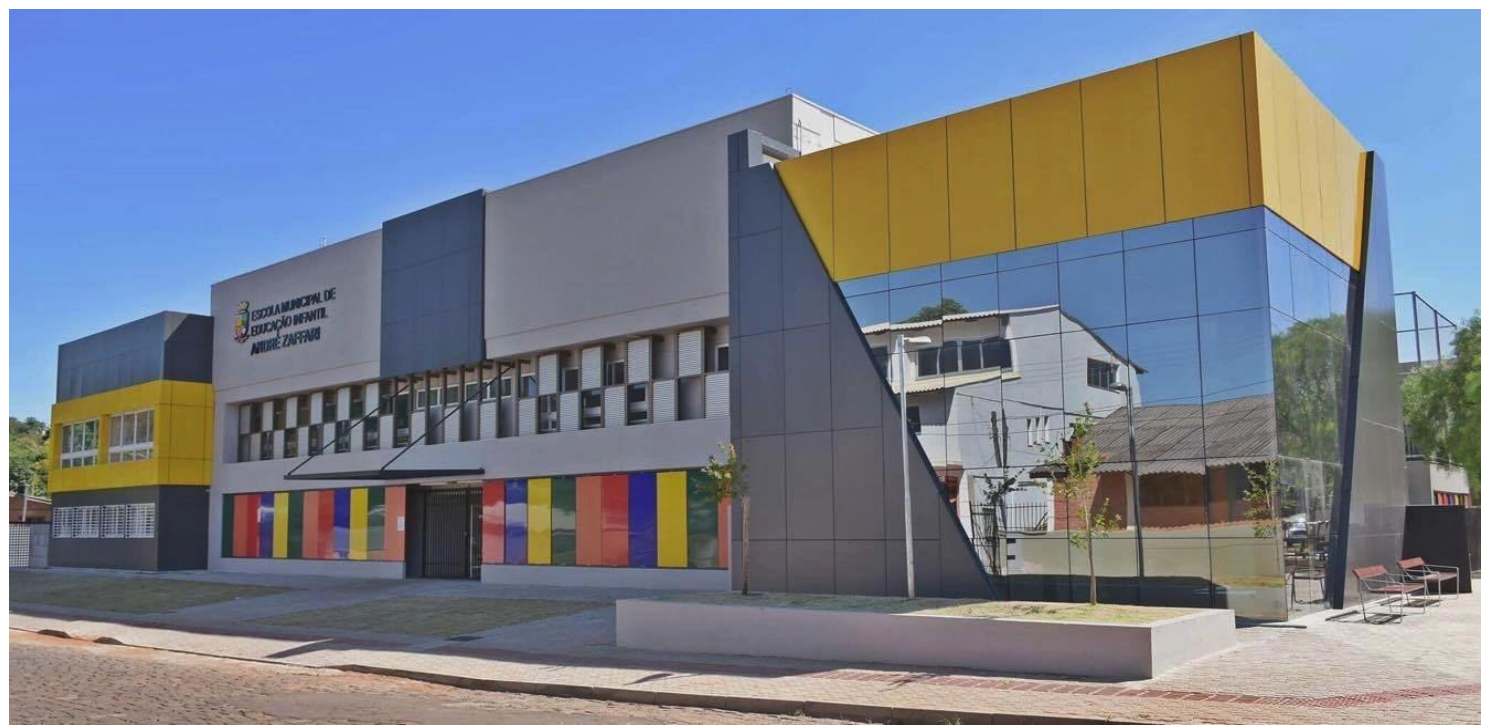

Fonte: Jornal Diário da Manhã, 2017. 


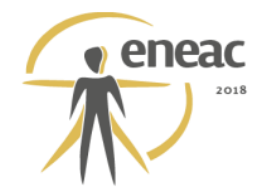

A justificativa pela escolha destas salas foi determinada pelo seu uso (pré-escola, maternal e sala de atividades), sendo que as demais salas da escola não foram avaliadas conforme Figura 2 (PEREIRA et al., 2017).

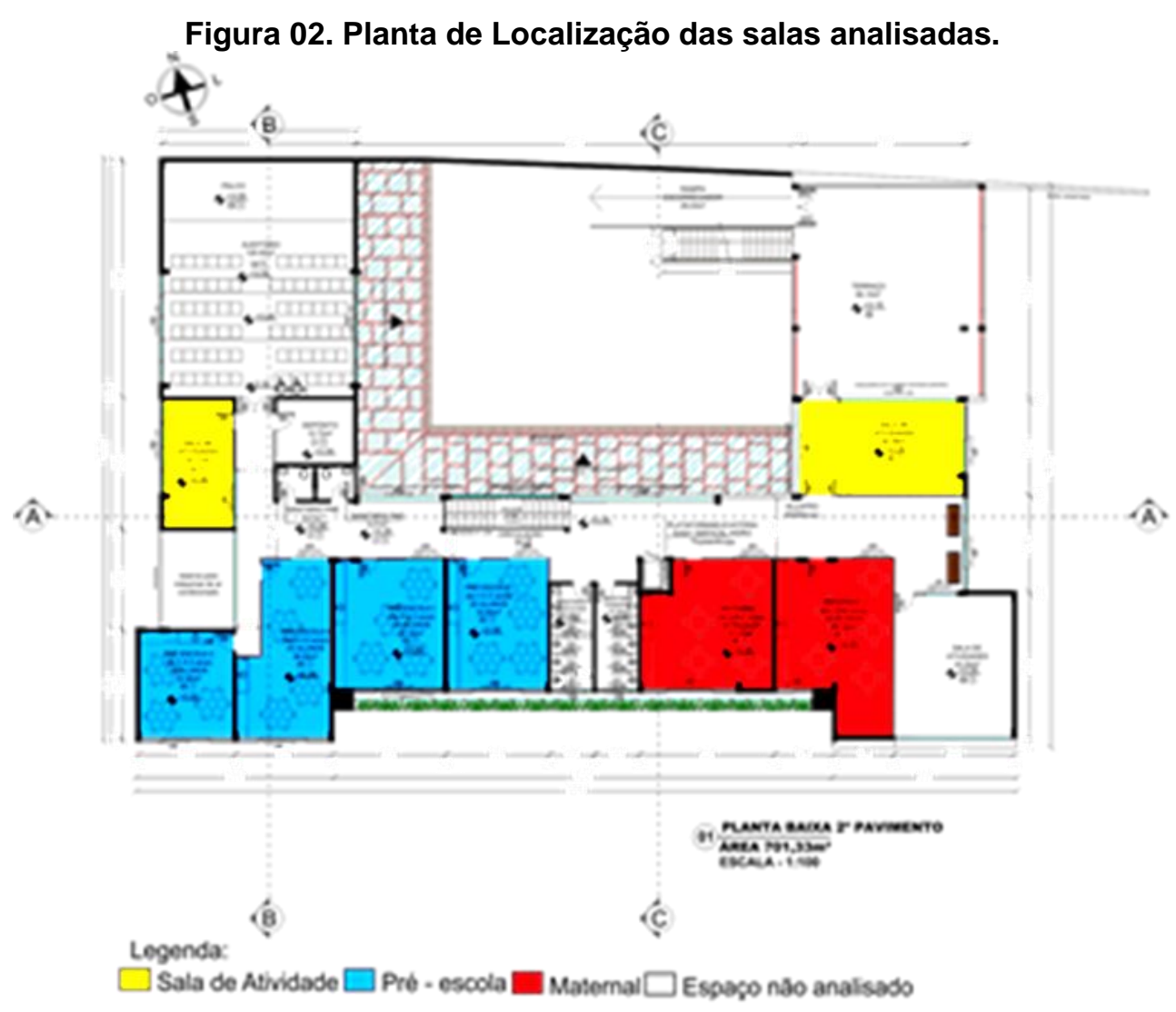

Fonte: Battisti (2015), adaptada por PEREIRA et al. (2017).

\subsubsection{MEDIÇÕES TÉCNICAS}

Foram realizadas as medições de temperatura e umidade relativa do ar com auxílio do Psicrômetro Py 5000, modelo ICEL manus, medições de conforto lumínico com Digital Luz Mester MLM-1011, e levantamento do nível de ventilação por meio do anemômetro Instrutherm TAD-500. Os locais de coleta foram determinados em caráter exploratório, de acordo com Cardoso et al. (2016): nas salas retangulares foram colocados cinco pontos em distantes um metro de cada parede, e um localizado no centro, todos posicionados a um metro de altura. Já nas salas não retangulares, os locais das medições seguiram o esquema conforme Figura 3 (PEREIRA et al., 2017). 


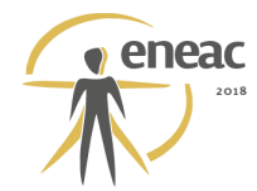

Figura 03. Planta de localização dos pontos de medição em uma das saldas de aula.

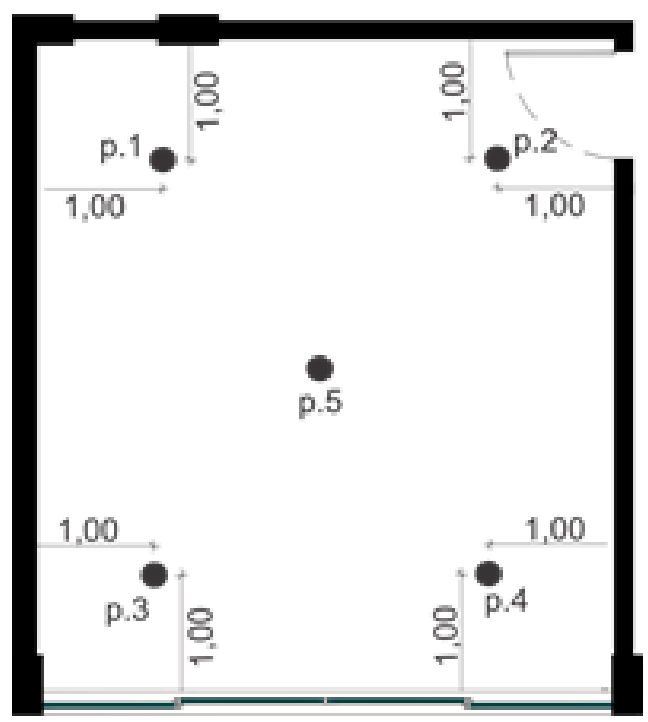

Fonte: PEREIRA et al. (2017).

O delineamento das medições nos ambientes ocorreu conforme as atividades que estavam sendo exercidas, sendo que algumas salas não estavam em uso. Devido às condições meteorológicas do dia de coleta dos dados (23 de maio de 2017, período da manhã, com céu nublado e chuvoso), nas salas em uso a iluminação artificial foi necessária, além de algumas janelas estarem fechadas por opção das professoras. Nas salas não utilizadas durante este período, foram verificadas as condições de iluminação natural (PEREIRA et al., 2017).

Para a identificação dos sistemas construtivos foi realizado o método de walkthrough com acompanhamento da diretora da escola no qual os materiais construtivos dos ambientes analisados são especificados. Esse método de análise consiste em um percurso dialogado que possibilita a observação e familiarização do espaço físico, sendo útil para identificar as principais potencialidades do ambiente, assim como os aspectos negativos (RHEINGANTZ, 2009). O sistema construtivo identificado segue o mesmo padrão em todas as salas analisados com piso vinílico em azul, bege e cinza, paredes externas em bloco de cerâmicas furadas com espessura de $20 \mathrm{~cm}$ pintadas internamente nas cores azul e gelo, paredes internas em Drywall pintadas em azul e gelo. Janelas externas de perfil de alumínio branco e vidro duplo e janelas internas com perfil de alumino brando com vidro simples. Forro de gesso pintado em branco. As luminárias do tipo led (PEREIRA et al., 2017).

\section{DISCUSSÃO E RESULTADOS}

A metodologia para sistematização e representação dos resultados obtidos em campo baseou-se nos estudos de Göçer, Hua e Göçer (2015), que analisaram como os procedimentos de Avaliação Pós-Ocupação podem trazer informações que enriqueçam o processo de projeto das edificações por meio do uso do BIM, possibilitando visualizar tanto medições in loco, quanto informações oriundas de questionários, a partir de uma escala de cores no ambiente de modelagem tridimensional (PEREIRA et al., 2017).

O projeto da Escola André Zaffari, originalmente concebido por meio do software AutoCAD, em 2D, foi representado por meio de um modelo tridimensional elaborado em Autodesk Revit 2017 (Figura 04), contando com informações relacionadas aos materiais empregados e sistemas construtivos, com base no memorial descritivo. Assim, foi elaborado um modelo 


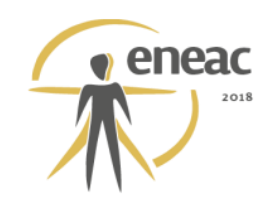

genérico de toda a edificação, porém a aplicação do artigo restringiu-se aos compartimentos do nível superior, onde foram realizadas as medições em campo (PEREIRA et al., 2017).

Figura 04 - Modelo da escola elaborado em plataforma BIM

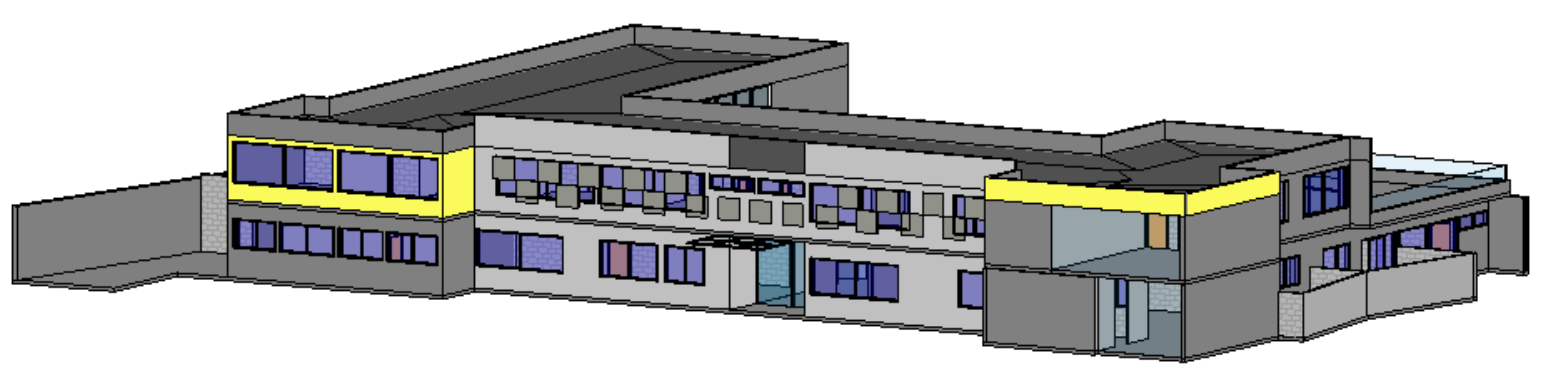

Fonte: PEREIRA et al. (2017).

Para a criação do banco de dados com os parâmetros de conforto ambiental, foi utilizado o programa Microsoft Excel, no qual medições acerca da temperatura, umidade e iluminação das salas foram organizadas por ambiente visitado (PEREIRA et al., 2017).

De modo a viabilizar a computação de resultados de medições e percepção no banco de dados, foi programada uma ferramenta através do ambiente Dynamo - uma extensão para Revit, que permitiu a customização de funcionalidades por meio de VPL (Visual Programming Language) (DYNAMO, 2017; PEREIRA et al., 2017).

No Dynamo, um algoritmo foi desenvolvido para captar as informações da planilha de Excel, incorporando os dados das medições e percepções no modelo BIM, através da sincronização do pareamento dos nomes de ambientes da planilha com os nomes de ambientes (rooms) do Revit (PEREIRA et al., 2017).. O algorítmo então possibilita visualizar a graficação em planta dos resultados, utilizando uma escala de cores proporcionando uma nova forma de análise para as ferramentas de APO (PEREIRA et al., 2017).

Nas figuras 05, 06 e 07 é possível visualizar por meio de uma escala de cores os níveis de umidade, temperatura e iluminação de cada ambiente, respectivamente. Como as medições foram realizadas em cinco pontos nos ambientes, 0 valor médio foi utilizado na representação das cores (PEREIRA et al., 2017). 


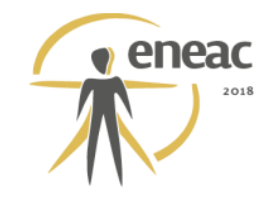

Figura 05 - Mapeamento de medições de umidade no ambiente BIM

\section{(4)}

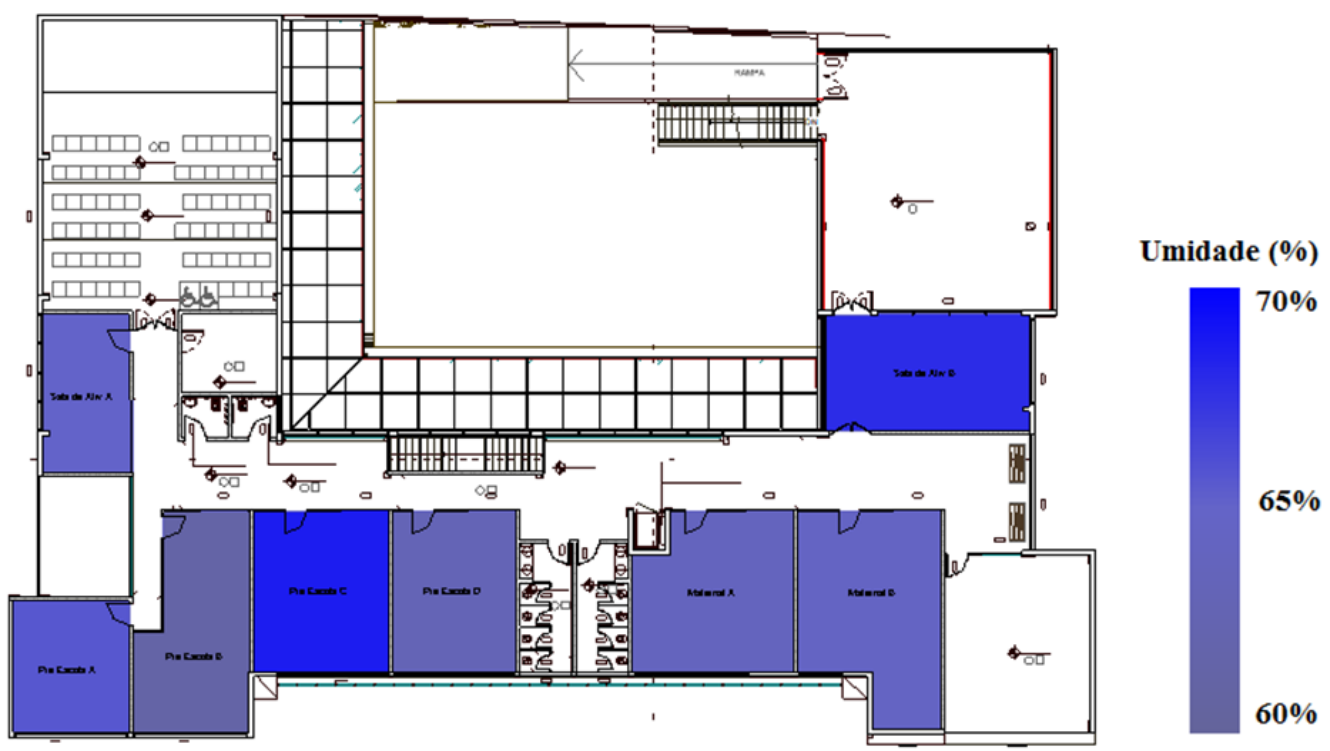

Fonte: PEREIRA et al. (2017).

Figura 06 - Mapeamento de medições de temperatura no ambiente BIM (4)

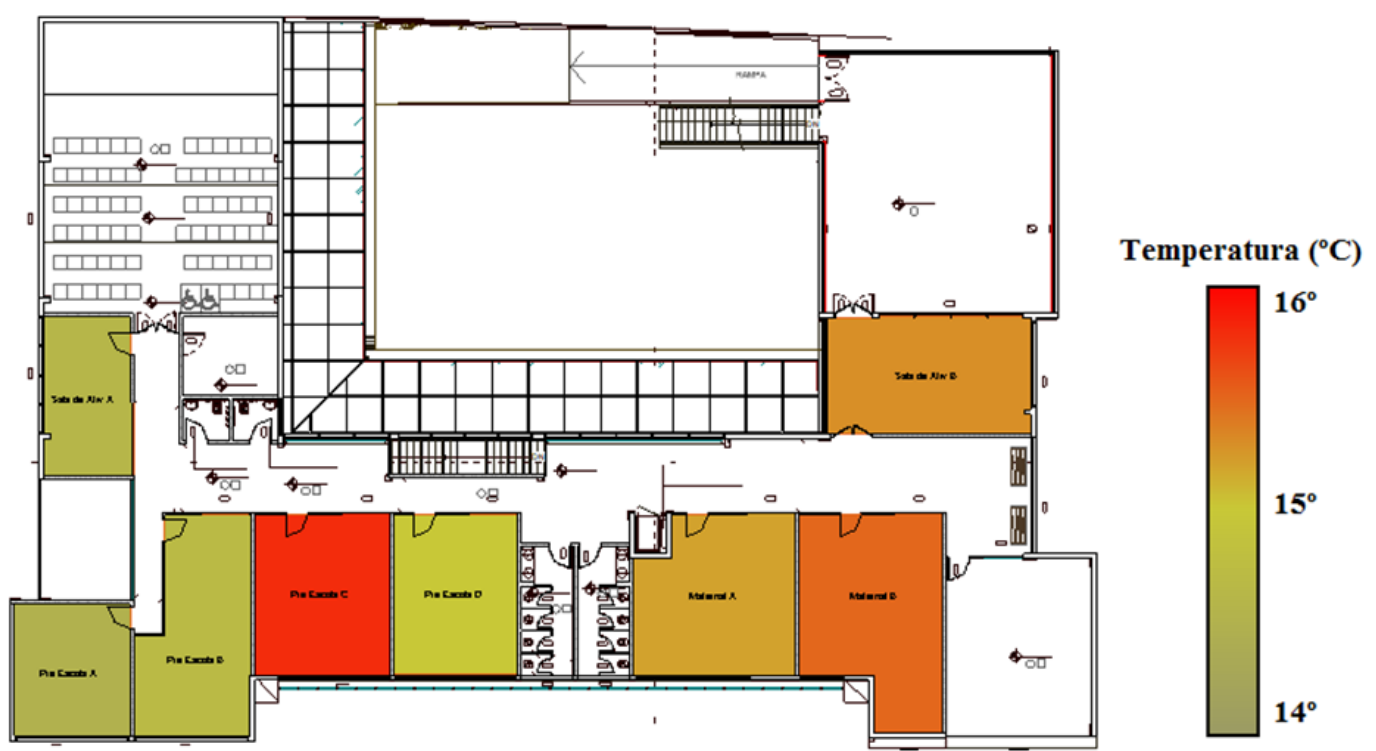

Fonte: PEREIRA et al. (2017). 


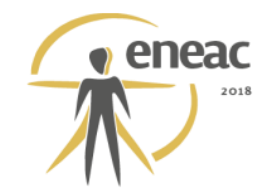

Figura 07 - Mapeamento de medições de desempenho lumínico no ambiente BIM

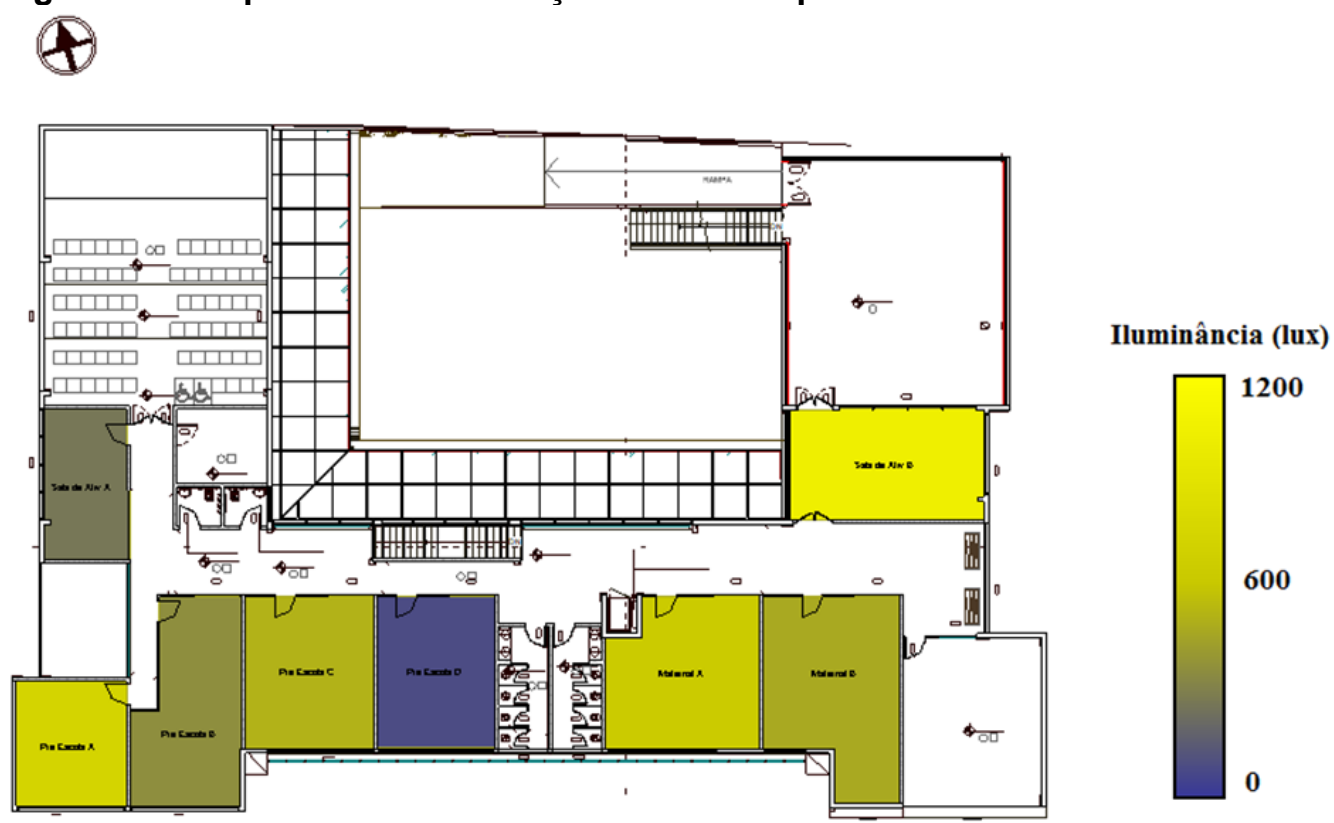

Fonte: PEREIRA et al. (2017).

Após a inserção dos dados coletados na Plataforma BIM, verificou-se que em relação à umidade relativa as salas mantiveram uma porcentagem em torno de 65 . $O$ valores altos para a umidade relativa também justificam as temperaturas coletadas, que tiveram uma média de $15^{\circ} \mathrm{C}$. Este fato deve-se às condições do tempo meteorológico no dia da coleta, céu nublado com chuva intensa, mas intermitente (PEREIRA et al., 2017).

Por este mesmo motivo, as salas em uso durante as medições estavam com as luzes acesas, impossibilitando a medição da iluminação natural. Essa limitação gerou resultados discrepantes na análise de desempenho lumínico, mas, por outro lado, foi possível averiguar a eficiência da plataforma BIM em evidenciar os resultados graficamente. As salas sem uso, mas com pouca ou sem luz natural tiveram resultados próximos a zero, enquanto que as salas em uso atingiram valores médios próximos a 600 lux (PEREIRA et al., 2017).

A apresentação dos resultados por meio de imagens facilita o entendimento geral dos parâmetros relacionados ao conforto, sendo um instrumento na tomada de decisões gerais durante o processo de projeto (PEREIRA et al., 2017). No entanto, as análises para determinação das reais condições de conforto devem seguir outras recomendações estabelecidas nas normas brasileiras. Para DA GRAÇA; KOWALTOWSKI; PETRECHE (2007), a visualização das informações técnicas de conforto térmico permite definir melhor o projeto, de modo a evitar retrabalho ou adaptações pós-construção.

\section{CONSIDERAÇÕES FINAIS}

Ressalta-se que as avaliações e análises técnicas realizadas foram limitadas, no entanto, foram compatíveis com o objetivo deste estudo de caso, pois possibilitaram uma investigação preliminar, tanto dos ambientes escolares, quanto da utilização da plataforma BIM como ferramenta de análise de dados, por meio de esquemas gráficos. As imagens geradas possibilitaram a visualização prévia do conforto dos ambientes. Futuramente, com o banco de dados estabelecido, novas medições e aplicação de entrevistas poderão ser feitas para melhorarias na avaliação. 


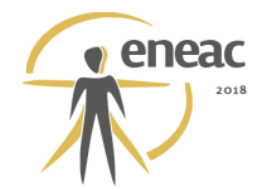

Uma das contribuições deste trabalho é a experiência de aplicação de conceitos de APO em software BIM, onde foi possível representar os dados de medições por meio das escalas de cores. Tal experiência viabilizará futuramente a comparação entre os resultados obtidos em certas interações com informações sobre geometria, aberturas e materiais nos respectivos ambientes, através da modelagem BIM (PEREIRA et al., 2017). Espaços escolares requerem constantes estudos e adaptações para que se tornem inclusivos e benéficos à saúde e bemestar dos alunos, professores e funcionários. Desta forma, através de pesquisas neste âmbito, é possível gerar recomendações arquitetônicas baseadas no aporte científico, assegurando maior qualidade nos ambientes construídos (PEREIRA et al., 2017).

Contudo, mais estudos são necessários para aprimorar o banco de dados estabelecido e possibilitar abordagens mais representativas, sobretudo em relação às possíveis aplicações de questionários e medições em outros ambientes, bem como a incorporação de simulações para fins de comparação (PEREIRA et al., 2017). Há, porém, uma base de dados expansível ligada ao algorítmo desenvolvido na extensão Dynamo, que poderá ser amplificada e melhorada para abranger diferentes metodologias de APO em sua interface (PEREIRA et al., 2017).

\section{AGRADECIMENTOS}

Os autores agradecem a colaboração da Secretaria de Educação do munícipio de Passo Fundo-RS, à direção, professores e funcionários da Escola Municipal de Educação Infantil André Zaffari, e aos mestrandos que realizaram o trabalho da disciplia de Avaliação Pós-Ocupação e o Processo de Projeto, do Programa de Pós-Graduação Stricto sensu em Arquitetura e Urbanismo (PPGARQ-IMED), no período de 2017.1: PEREIRA, Bruna S.; MOREIRA, Denise A.; PAZINI, Ernani Z.; SARAIVA, Gabriela H.; SILVA, Juliano L.; COSTA, K.; FERRI, Mariane B.; MELLO, Marina B.; ZARDO, Paola; FOGAÇA, Paula; WINTER, Renato.

\section{REFERÊNCIAS BIBLIOGRÁFICAS}

CARDOSO, GRACE TIBERIO; VISENTIN, T; BENINCA, L.; NECKEL, A. . Post-Occupancy Evaluation for a school building: a case study in the city of Passo Fundo/RS - Brazil. In: Passive Low Energy Architecture - Design to Thrive, 2017, Edinburgh. Proceedings of 33rd PLEA International Conference Design to Thrive. Edinburgh: NCEUB 2017 - Network for Comfort and Energy Use in Buildings, 2017. v. 2. p. 2483-2490.

CARDOSO, Grace Tibério; VECCHIA, Francisco; NECKEL, Alcindo. Climatology Applied To Architecture: An Experimental Investigation about Internal Temperatures Distribution at Two Test Cells. Journal of Engineering Research and Applications, v. 6, n. 4, p. 07-13, 2016.

DYNAMO. Dynamo BIM. 2017. Disponível em < http://dynamobim.org/>. Acesso em 15 de junho de 2017.

GERRISH, T.; RUIKAR, K.; COOK, M.; JOHNSON, M.; PHILLIP, M. BIM application to building energy performance visualization and management: Challenges and potential. Energy and Buildings, $v$. 144, p. 218-228, 2017.

GÖÇER, Ö.; HUA, Y.; GÖÇER, K. Completing the missing link in building design process: Enhancing post-occupancy evaluation method for effective feedback for building performance. Building And Environment, v. 89, p.14-27, 2015.

OCHOA, Juliana Herlemann; ARAÚJO, Daniel Lima; SATTLER, Miguel Aloysio. Análise do conforto ambiental em salas de aula: comparação entre dados técnicos e a percepção do Usuário. Thermal comfort analysis in classrooms: comparison between technical data and occupants' perception. Ambiente Construído, Porto Alegre, v. 12, n. 1, p. 91-114, jan./mar. 2012. 


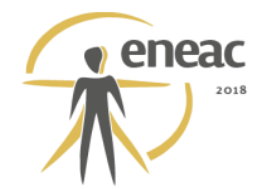

PEREIRA, B. S.; MOREIRA, D. A.; PAZINI, E. Z.; SARAIVA, G. H.; SILVA, J. L.; COSTA, K.; FERRI, M. B.; MELLO, M. B.; ZARDO, P.; FOGAÇA, P.; WINTER, R. Incorporação de resultados de avaliação pós-ocupação de escola em modelo BIM. Trabalho apresentado como requisito parcial para aprovação na Disciplina Avaliação Pós-Ocupação e o Processo de Projeto, Programa de PósGraduação Stricto sensu em Arquitetura e Urbanismo, Faculdade Meridional, Passo Fundo, 2017.

PREISER, Wolfgang FE; VISCHER, Jacqueline C. The evolution of building performance evaluation: An introduction. Assessing building performance, p. 3-14, 2005.

SUCCAR, B. Building Information Modelling: conceptual constructs and performance improvement tools. 2013. 370 f. Tese (Doutorado) - University of New Castle, Callaghan, 2013.

VISENTIN, TALES GONÇALVES ; CARDOSO, Grace Tibério ; BENINCÁ, LETIANE . Arquitetura Bioclimática: Avaliação Pós Ocupação (APO) em escola pública estadual. REVISTA DE ARQUITETURA IMED, v. 6, p. 49-61, 2017.

DA GRAÇA, Valéria Azzi Collet; KOWALTOWSKI, Doris Catharine Cornelie Knatz; PETRECHE, João Roberto Diego. An evaluation method for school building design at the preliminary phase with optimisation of aspects of environmental comfort for the school system of the State São Paulo in Brazil. Building and Environment, v. 42, n. 2, p. 984-999, 2007. 